\title{
TESTING THE UNIFORMITY OF SPRAY DISTRIBUTION UNDER DIFFERENT APPLICATION PARAMETERS
}

\author{
Alaa SUBR ${ }^{1}$, Marek MILANOWSKI ${ }^{2}$, Stanisław PARAFINIUK ${ }^{2}$, Józef SAWA ${ }^{3}$ \\ ${ }^{1}$ Department of Agricultural Machines and Equipment, College of Agriculture, University of Baghdad, IRAQ \\ ${ }^{2}$ Department of Machinery Exploitation and Management of Production Processes, University of Life \\ Sciences in Lublin, POLAND \\ ${ }^{3}$ The East European State Higher School in Przemyśl, POLAND \\ E-mail of corresponding author: alaa.kamel@coagri.uobaghdad.edu.iq
}

Keywords: spray distribution, coefficient of variation (CV), spray angle, agricultural nozzles

\begin{abstract}
The study was conducted to determine the differences between commonly used nozzles TeeJet XR110-03 (new and used) during the testing of field boom sprayers on an electronic table (spray scanner) as they were affected by spraying pressure. The tests were carried out at three working pressures $(2.0,3.0$ and 4.0 bar) and the uniformity of spraying, the liquid flow rate of the spray nozzles mounted on the field boom and the number of nozzles beyond the tolerance were determined. The spraying angle was also measured which could influence the coefficient of variation (CV) of the spray distribution. The results showed a poor CV value (more than 10\%) as the operating pressure decreased for the new nozzles while they were (CV values) under $10 \%$ for the used nozzles at all the range of test pressure values. This suggests that the spray distribution uniformity test depends on the sprayer boom setting and operating factors more than on the work life of the nozzles.
\end{abstract}

\section{INTRODUCTION}

Ensuring a uniform placement of the applied materials (pesticide) to the target (pest) is an important task for the sprayer operator which requests careful setting for the sprayer. This factor (spray distribution) which is expressed by the coefficient of variation $(\mathrm{CV}, \%)$ could influence obtaining the required (maximum) efficiency of chemical crop protection with minimum costs and environmental contamination (Višacki et al., 2016). According to ISO 5681(1992), the transverse distribution defined as "Variation in volume or mass of spray liquid or granular deposited over the treated area transverse to the direction of travel" and the spray angle "Angle formed close to a spray nozzle by the edges of the spray". The CV is an indicator for the differences in the total measured spray deposit, the measured CV value from the field deposit must be $15 \%$ or less when applying pesticide on soil, grass, or weed surfaces (Willcutt and Smith, 2010). The same threshold (CV=15\%) was proposed by Herbst and Wolf (2001) as a performance limit for dynamic spray distribution. On the other hand, the laboratory CV value is usually smaller (numerically) than the value which was measured under the field condition (Smith, 1992). ISO 16122-2 (2015) set a threshold for the uniformity of the spray distribution within the total overlapped range, the coefficient of variation $(\mathrm{CV})$ according to this standard must be $10 \%$ or less.

Dorr and Pannell (1992) found in their study that more profit sensitivity of herbicide dose non- uniformity happened due to the nozzle design, the wind, boom roll, etc. than those which happened because of the boom overlapping (or the contrast) in successive circuits of the field. They reported that the estimated cost of the herbicide non-uniformity was as high as $25 \%$ of net returns in some scenarios. This non-uniformity of the spray distribution will cause less or over dose transfer of the pesticide to the target which, in turn, will affect the pesticide 
application process efficiency. The agricultural nozzles are the part which has the main effect on the spray distribution, besides the settings which were associated with those nozzles like nozzles height, nozzles spacing, spray angle and atomizing pressure etc. Because of their fan shape spray, flat fan nozzles need to be completely overlapped to gain uniform amount of spray under the nozzle tip (over the target) and also on the edges of the spray. This overlapping is affected by the spray angle of the nozzles which, in turn, is affected by the atomization pressure. However, increasing the last factor (pressure) does not ensure constant uniformity of the spray distribution for some types of nozzles (injector nozzles) in comparison with flat jet nozzles as stated by Višacki et al. (2016). There are other factors which affect the spray distribution in the dynamic mode (during spraying) like the vibration of the sprayer boom due to the field ground unevenness and the wind direction. Luck et al. (2015) reported an improvement in the CV values of the spray pattern uniformity when spraying at higher pressure values or at mid-range metering stem positions for the variableorifice nozzle. The objectives of this paper were:

1) Study the influence of several variable application parameters on the uniformity of spray distribution (coefficient of variation (CV)) and spray angle for flat-fan nozzles (new and used) mounted on sprayer boom under laboratory conditions.

2) Determine if the evaluation of the nozzles performance depending on the test of spray distribution will represent the nozzle physical state and give an indicator to replace the nozzles according to the sprayer inspection procedure.

\section{MATERIALS AND METHODS}

All the spray distribution tests were done when the sprayer boom was static and with fixed height and spacing of nozzles. New and used (having more than $10 \%$ increase in flow rate than the nominal one) Flat fan nozzles were utilized in the test; their features and the boom setting are detailed in Table 1. The laboratory boom sprayer with electronic adjustment of pressure and sections work on/off was used in the experiment. An electric pump was used to transfer the tab water from the tank to the boom and pressurized it with 2.0, 3.0 and 4.0 bar pressure (within the recommended pressure from the manufacturer).

Table 1. Features of the test nozzles and their setting on the boom

\begin{tabular}{|c|c|}
\hline Nozzle & Spraying Systems Co. ${ }^{\circledR}$, TeeJet XR 110-03 \\
\hline Boom working width & $6 \mathrm{~m}$ \\
\hline Nozzles spacing & $0.5 \mathrm{~m}$ \\
\hline Boom height & $0.5 \mathrm{~m}$ \\
\hline Number of nozzles & 12 \\
\hline Nominal flow rate & $1.181 / \mathrm{min}$ at $3.0 \mathrm{bar}$ \\
\hline Application rate* & $300 \mathrm{l} / \mathrm{ha}$ \\
\hline
\end{tabular}

* Manually input to the patternator software

The coefficient of variation (CV) used to assess the uniformity of the spray transverse distribution; it was calculated by dividing the standard deviation of the collected water in 
every patternator tube under the boom by the average value of the total collected water (ISO 16122-2, 2015).

$$
C V=100 \times \frac{s}{\overline{\mathrm{x}}}
$$

where:

$$
\begin{gathered}
S=\sqrt{\frac{\sum\left(x_{i}-\bar{x}\right)^{2}}{n-1}} \\
\overline{\mathrm{x}}=\frac{\sum x_{i}}{n}
\end{gathered}
$$

$C V$ : coefficient of variation, expressed as percentage;

$x_{\mathrm{i}}$ : the volume of liquid in the $\mathrm{i}^{\text {th }}$ tube;

$n:$ the number of grooves;

$S:$ the standard deviation of the volumes collected in the grooves;

$\bar{x}:$ the average/mean volume collected per groove.

The electronically driven test bench "Sprayertest 2000" was used to measure the distribution uniformity and total sprayer output parameters (Figure 1). The device has a table $(2.12 \mathrm{~m}$ width with 20 measuring glasses) which contains a number of $20 \mathrm{~V}$ shaped channels. The table is fixed to a test coach which automatically moves on aluminum rails (18 $\mathrm{m}$ long). During the test and by online radio transmission, the data are displayed on a PC monitor. The device is accompanied with software (OWFB 1.0) to show graphically the spray distribution and calculate the $\mathrm{CV}$, average flow rate of the nozzles, total output of the boom, as well as to calculate the required travelling speed of the sprayer to gain a manually input application rate (set to 300 1/ha for all the test). The spray angle was measured by taking high-resolution photos of the spray with the help of LED light at different atomizing pressure. After this and with the help of software with protractor tool, the angle between the spray boundaries was measured.

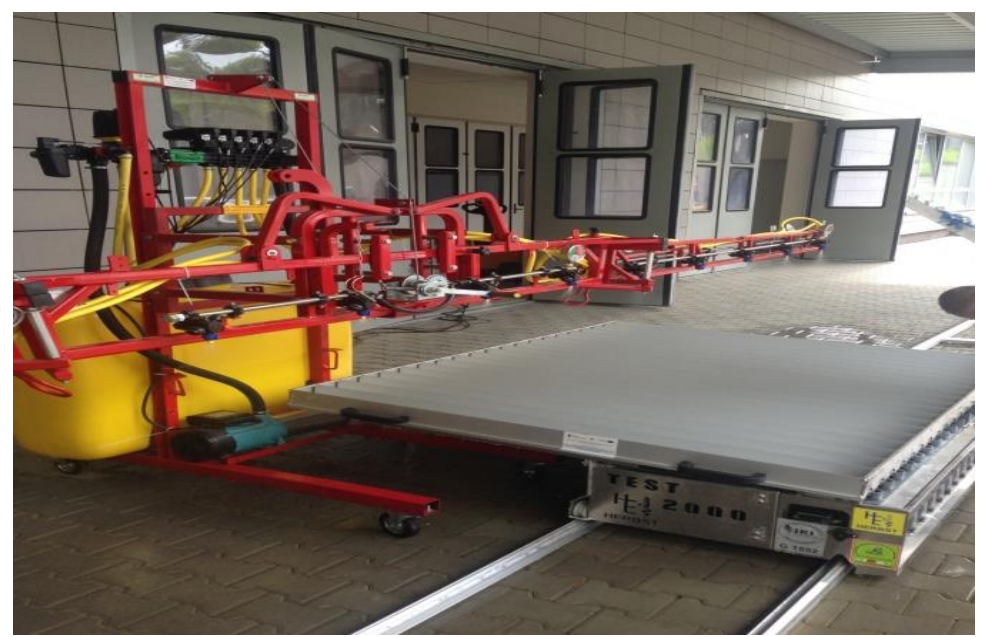

Figure 1. Sprayer test 2000 patternator and the laboratory sprayer boom used in the test 


\section{RESULTS}

Randomly chosen photographs of the boom spray distribution when spraying with new and used nozzles at 3.0 bar pressure are shown in Figure 2.
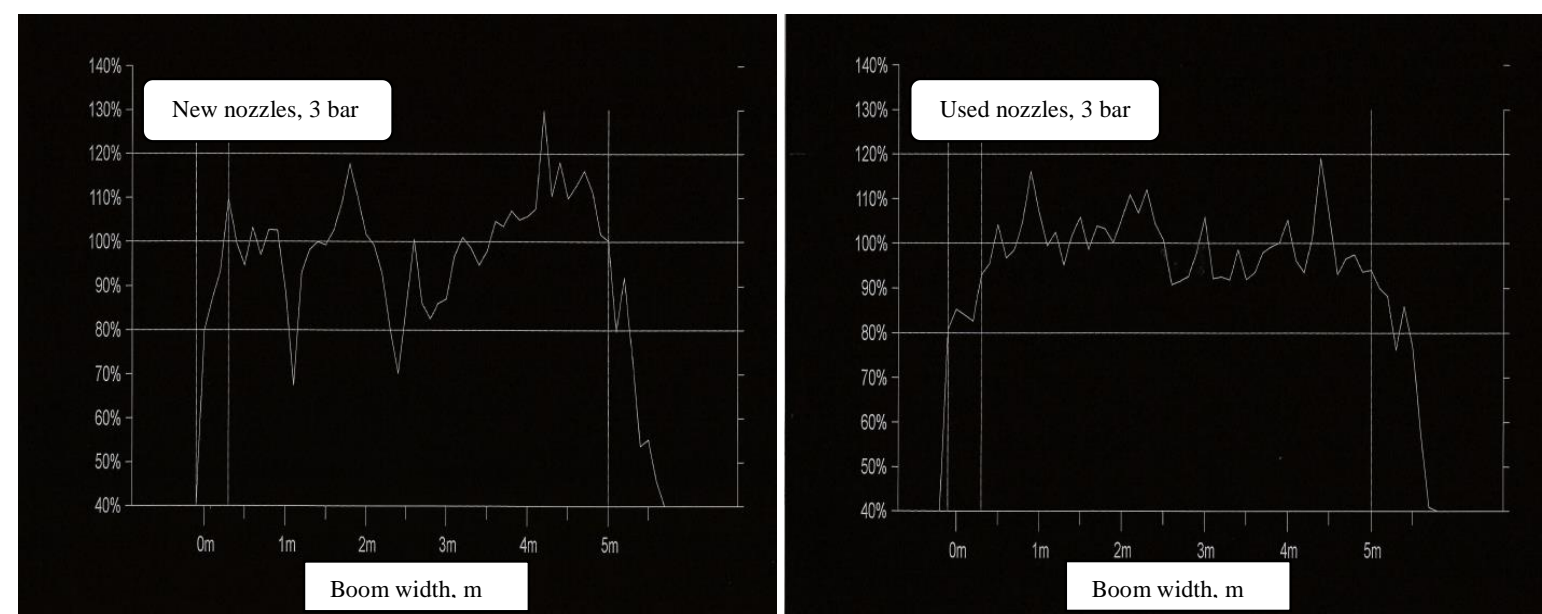

Figure 2.Spray distribution for new and used nozzles at 3.0 bar pressure, the vertical axis shows the collected values compared to the mean value

The previous figures indicate clearly that more new nozzles were out of tolerance than used nozzles. However, this number decreases as the spraying pressure for the new nozzles increased as shown numerically in Table 2. The number of used nozzles which were out of tolerance was the same for the three values of pressure (one nozzle only), and also the CV value was almost the same when using 3.0 and 4.0 bar pressure. Table 2 also shows the clear difference between the new and used nozzles concerning the flow rate (averaged value) which was increased as the spraying pressure increased for both new and used nozzles. This difference in the flow rate made the software to give higher spraying speed values (theoretical calculation) for the used nozzles than the new ones to keep the application rate $(300 \mathrm{l} / \mathrm{ha})$ in the same value.

Table 2 . The results of the spray distribution uniformity test

\begin{tabular}{|c|c|c|c|c|c|}
\hline \multirow{3}{*}{ Nozzles } & $\begin{array}{c}\text { Pressure, } \\
\text { bar }\end{array}$ & $\begin{array}{c}\text { Flow rate, } \\
1 / \text { min (SD) }\end{array}$ & $\begin{array}{c}\text { CV, \% } \\
(\mathrm{SD})\end{array}$ & $\begin{array}{c}\text { Number of } \\
\text { nozzles out of } \\
\text { tolerance }\end{array}$ & $\begin{array}{c}\text { Required } \\
\text { traveling } \\
\text { speed, km/h }\end{array}$ \\
\hline \multirow{4}{*}{ New } & 2.0 & $0.81(0.03)$ & $13.6(0.8)$ & 6 & 3.70 \\
\cline { 2 - 6 } & 3.0 & $0.98(0.05)$ & $12.1(0.7)$ & 5 & 3.70 \\
\cline { 2 - 6 } & 4.0 & $1.17(0.03)$ & $9.4(0.8)$ & 2 & 5.30 \\
\hline \multirow{3}{*}{ Used } & 2.0 & $1.08(0.03$ & $6.9(1.4)$ & 1 & 4.72 \\
\cline { 2 - 6 } & 3.0 & $1.36(0.04)$ & $7.4(1.0)$ & 1 & 5.86 \\
\cline { 2 - 6 } & 4.0 & $1.54(0.06)$ & $7.5(0.9)$ & 1 & 6.62 \\
\hline
\end{tabular}

From Figure 3 we can notice the $\mathrm{CV}$ value for the new nozzles spray was decreased as the spraying pressure increased and finally it becomes within the allowed limits according to the 
sprayer inspection standard (ISO 16122-2, 2015) when using 4.0 bar pressure for the test. On the other hand, the used nozzles CV value was within the allowed limits when using all the test pressure values.

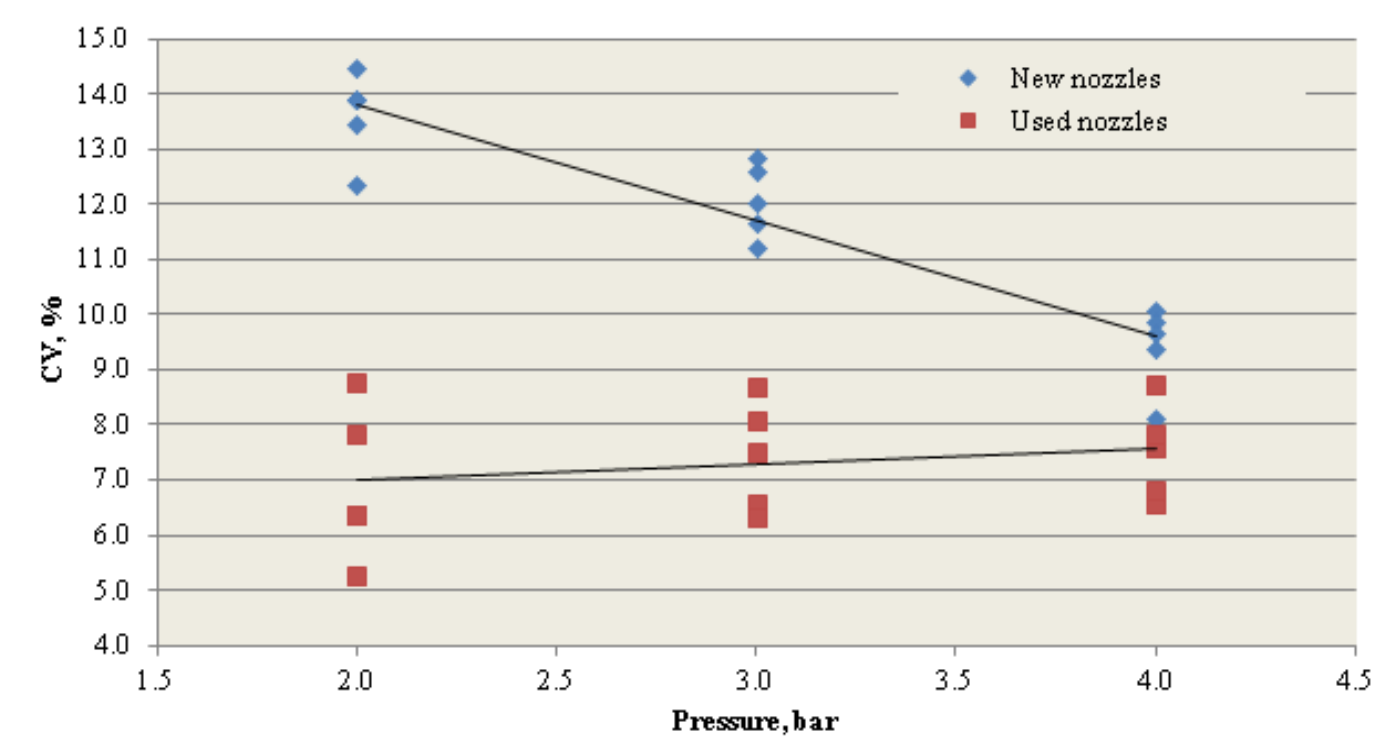

Figure 3. Coefficient of variation (CV) for new and used nozzles at different atomizing pressure

This change in the $\mathrm{CV}$ values for the new nozzles (poor values or over $10 \%$ as the operating pressure decreased) probably results from the effect of spray angle which was changed due to the increase in pressure as well (Figure 4).

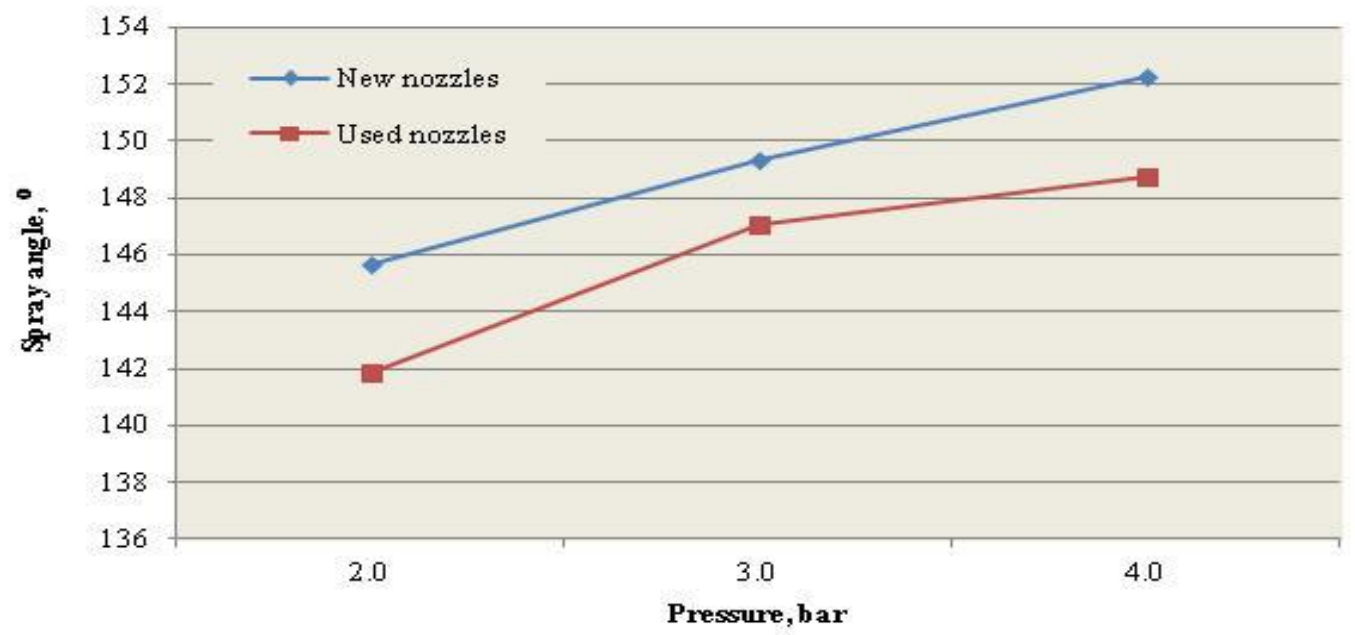

Figure 4. Effect of atomizing pressure on the spray angle

This implies that there is some specific setting for the nozzle and the boom where the CV value reaches the lowest value. In contrast, if all factors influencing this setting were not matched to reach the lowest spray distribution $\mathrm{CV}$ value, this test (uniformity of distribution test) could produce wrong information concerning the situation of the sprayer. The results of the used nozzles make this clearer, those nozzles were out of the limits according to the flow 
rate (it must be less than $10 \%$ increase than the nominal flow rate). However, from the distribution uniformity test, we can see that those nozzles were within the allowed CV limits for the sprayer inspection and for all the used spraying pressure.

\section{CONCLUSIONS}

From the results and within the scope of this study, the following can be concluded:

1. The spray distribution CV values are higher than $10 \%$ for new nozzles at 2.0 and 3.0 bar pressure and less than $10 \%$ at 4.0 bar pressure. The CV values depend more on the setting and adjustment of the sprayer working parameters than on the physical condition of the nozzles.

2. Depending on the spray distribution uniformity test during the sprayer inspection procedure will result in acceptance of nozzles set which are used and are out of the flow rate tolerance limits, within the range of pressure used in the test.

\section{REFERENCES}

Dorr, G. J., \& Pannell, D. J. (1992). Economics of improved spatial distribution of herbicide for weed control in crops. Crop Protection, 11(4), 385-391.

Herbst, A., \& Wolf, P. (2001). Spray deposit distribution from agricultural boom sprayers in dynamic conditions. In 2001 ASAE Annual Meeting (p. 1). American Society of Agricultural and Biological Engineers.

ISO 16122-2. (2015). Agricultural and forestry machinery - Inspection of sprayers in use - Part 2: Horizontal boom sprayers. $18 \mathrm{p}$.

ISO 5681., (1992). International standard. Equipment for crop protection - Vocabulary. 16 p.

Luck, J. D., Pitla, S. K., Sama, M. P., \& Shearer, S. A. (2015). Flow, spray pattern, and droplet spectra characteristics of an electronically actuated variable-orifice nozzle. Transactions of the ASABE, 58(2), 261269.

Smith, D. B. (1992). Uniformity and recovery of broadcast sprays using fan nozzles. Transactions of the ASAE, 35(1), 39-44.

Višacki, V. V., Sedlar, A. D., Gil, E., Bugarin, R. M., Turan, J. J., Janic, T. V., \& Burg, P. (2016). Effects of sprayer boom height and operating pressure on the spray uniformity and distribution model development. Applied Engineering in Agriculture 32(3), 341-346.

Willcutt, H. M. H., \& Smith, D. B. (2010). Improving the uniformity of ground-applied broadcast sprays. 